\title{
A DERROCADA POLÍTICA DE JACOB ZUMA NO TRAÇO DE ZAPIRO
}

\author{
Renata de Paula dos Santos ${ }^{1}$ \\ Rozinaldo Antonio Miani ${ }^{2}$
}

\begin{abstract}
Resumo: O presente artigo analisa algumas charges que representam a historiografia recente da África do Sul, a partir do traço de Jonathan Shapiro. O profissional, mais conhecido como Zapiro, se destaca entre os artistas do traço mais influentes do seu país. Os argumentos, verificados a partir da análise do discurso chárgico, apresentam características pessoais e políticas do ex-presidente do país, Jacob Zuma. Ele renunciou ao cargo em fevereiro de 2018, após pressões de seu próprio partido. Zuma acumula mais de 800 denúncias de corrupção e, em 2006, foi a julgamento, acusado de ter estuprado uma jovem portadora de HIV. Entre os autores que fundamentam este trabalho, destacam-se Carlin (2009), Romualdo (2000), Santos (2014) e Miani (2005; 2012).
\end{abstract}

Palavras-chave: África do Sul; Jacob Zuma; Zapiro; Charge; Zuma Shower.

\section{THE POLITICAL OVERTHROW OF JACOB ZUMA IN THE TRAIT OF ZAPIRO}

Abstract: This article analyzes some charges that represent the recent historiography of South Africa, from the trait of Jonathan Shapiro. The professional, better known as Zapiro, stands out among the most influential trace artists of his country. The arguments, verified from the analysis of the cartoon's discourse, present characteristics people and policies of the expresident of the country, Jacob Zuma. He resigned from office in February 2018, following pressure from the party itself. Zuma raises more than 800 allegations of corruption and, in 2006, went on trial accused of raping a young woman with HIV. Among the authors that base this work, stand out Carlin (2009), Romualdo (2000), Santos (2014) and Miani (2005; 2012).

Keywords: South Africa; Jacob Zuma; Zapiro; Cartoon; Zuma Shower.

\section{LA DERROTA POLÍTICA DE JACOB ZUMA EN EL TRAZADO DE ZAPIRO}

Resumen: El presente artículo analiza algunas charges que representan la historiografía reciente de Sudáfrica, a partir del guión de Jonathan Shapiro. El profesional, más conocido como Zapiro, se destaca entre los artistas del trazado más influyentes de su país. Los argumentos, verificados a partir del análisis del discurso chárgico, presentan características personales y políticas del ex-presidente del país, Jacob Zuma. Él renunció al cargo en febrero de 2018, tras presiones del propio partido. Zuma acumula más de 800 denuncias de corrupción y en 2006 fue acusado de haber violado a una joven portadora de VIH. Entre los autores que fundamentan este trabajo, destacan Carlin (2009), Romualdo (2000), Santos (2014) y Miani (2005; 2012).

Palabras clave: Sudáfrica; Jacob Zuma; Zapiro; Charge; Zuma Shower.

\footnotetext{
${ }^{1}$ Mestre em Comunicação pela Universidade Estadual de Londrina (UEL). Docente na Faculdade Pitágoras de Londrina.

${ }^{2}$ Doutor em História pela Universidade Estadual Paulista "Júlio de Mesquita Filho", Unesp. Docente do Programa de Pós-Graduação em Comunicação da UEL.
} 


\section{INTRODUÇÃO}

A produção historiográfica mais recente tem incorporado de maneira bastante significativa a charge e as demais modalidades do humor gráfico como importantes fontes históricas. Nesse sentido, a história recente da África do Sul pode ser contada e analisada por meio das charges de Zapiro, um dos artistas do traço mais influentes do seu país.

Desde a libertação de Mandela e, posteriormente, a sua eleição como presidente, a África do Sul conheceu um novo capítulo em sua história. O período pós-apartheid representou a ascensão de uma democracia multirracial que contou com o protagonismo do Congresso Nacional Africano (CNA) que nasceu como movimento em defesa dos direitos da população negra do país e se tornou o principal partido político da África do Sul.

Nas fileiras do CNA, além de Mandela, estavam vinculados os principais militantes da luta antiapartheid e, dentre eles, os respectivos sucessores de Mandela na Presidência da África do Sul: Thabo Mbeki (1999-2008) e Jacob Zuma (2009-2018). Outro aspecto comum entre esses dois últimos presidentes sul-africanos é que eles renunciaram a seus cargos por suspeitas e denúncias de corrupção.

No caso de Jacob Zuma, a sua trajetória política foi marcada, dentre outros embates, por uma disputa simbólica (e também política) com o chargista Zapiro que realizou uma intensa e exaustiva obra chárgica, principalmente, denunciando suas práticas e comportamentos pessoais, considerados incompatíveis com sua posição e importância política no país, bem como retratando sua conduta questionável como líder político, marcada por inúmeras denúncias de corrupção.

Nesse contexto, este artigo se propõe a analisar algumas charges produzidas pelo chargista sul-africano Zapiro sobre o ex-presidente Jacob Zuma, desde as denúncias de ter cometido estupro, quando ainda era vice-presidente do país, até sua renúncia da Presidência em fevereiro de 2018. Além da análise do discurso chárgico, metodologia utilizada para o desenvolvimento do trabalho, também realizamos uma entrevista com o chargista. ${ }^{3}$

Para o cumprimento desse objetivo, começaremos apresentando um breve panorama do contexto da África do Sul após o fim do apartheid e a emergência da democracia multirracial. Além disso, ao longo do texto, serão identificados alguns aspectos polêmicos da

\footnotetext{
${ }^{3}$ A entrevista com Zapiro foi realizada via Skype em 02 de março de 2018. O chargista respondeu a uma lista de perguntas elaborada pelos autores contemplando principalmente a representação chárgica dos presidentes negros pós-apartheid, com destaque a Nelson Mandela e Jacob Zuma. Alguns trechos desta entrevista serão apresentados ao longo deste trabalho.
} 
trajetória pessoal e política de Jacob Zuma e, concomitantemente, apresentadas e analisadas algumas charges produzidas por Zapiro que pautaram e criticaram, com ironia e humor, o comportamento pessoal e a conduta política de Zuma como presidente da África do Sul, com especial atenção para a criação caricatural e simbólica do que ficou conhecido como Zuma Shower.

\section{ÁFRICA DO SUL, FIM DO APARTHEID E A DEMOCRACIA MULTIRRACIAL}

A década de 1990 foi decisiva para a história da África do Sul. Após sucessivos governos do Partido Nacionalista, o apartheid, sistema sócio-político estruturado na segregação racial, iniciado em 1948, deu lugar à democracia multirracial. Em 11 de fevereiro de 1990, o líder negro Nelson Mandela deixou a prisão após 27 anos encarcerado, acusado de desobediência. Os principais esforços do ativista foram pelo fim do regime segregacionista, pela realização de eleições gerais com a participação de todos os sul-africanos maiores de 18 anos e pela promulgação de uma nova Constituição no país.

John Carlin (2009) destaca que os quatro anos entre a libertação de Mandela e a chegada dele à Presidência da República foram marcados por intensos conflitos intertribais, opondo principalmente xhosas e zulus. Ao destacar os mesmos confrontos, os fotógrafos Greg Marinovich e João Silva (2003), que realizaram a cobertura do referido período como freelancers para as principais agências internacionais de comunicação, informaram que pelo menos 14 mil pessoas morreram nos conflitos. A rivalidade entre xhosas e zulus era intensificada pela participação do Estado. Os negros da etnia zulu - que integravam o Inkatha Freedom Party - eram partidários de Mangosuthu Buthelezi, aliado do Partido Nacionalista. Financiado pelo regime do apartheid, ele temia a chegada de Mandela à Presidência e assim, consequentemente, temia a perda dos privilégios que recebia. Tanto Carlin (2009) quanto Marinovich e Silva (2003) reforçam que a guerrilha interna tinha o objetivo de afetar a imagem de Mandela e do Congresso Nacional Africano (CNA), partido político que ele representava, junto à opinião pública e, consequentemente, dificultar o processo de transição para a democracia multirracial.

Em 1993, Nelson Mandela e Frederik Willem de Klerk, o último presidente do apartheid, foram os vencedores do Prêmio Nobel da Paz pelos esforços para a transição à democracia multirracial. No ano seguinte, Mandela tornou-se o primeiro presidente negro da África do Sul, com a finalidade de fazer um governo de transição. De Klerk era o vice- 
presidente (SANTOS, 2014). Analistas consideram que o líder negro foi o responsável por consolidar as bases para a democracia sul-africana. A Constituição aprovada após o fim do apartheid é considerada uma das mais democráticas do mundo. Críticos ponderam que o líder negro poderia ter sido mais combativo à corrupção, principalmente, no interior do próprio CNA, e deveria ter dado mais atenção no enfrentamento à AIDS.

Em 1999, Nelson Mandela deixou o cargo sem tentar a reeleição. Os sul-africanos elegeram Thabo Mbeki, também do CNA e com passado de militância antiapartheid. Ele chegou a se reeleger em 2004, mas renunciou ao mandato em 2008 por pressões do próprio partido e sob suspeita de corrupção. A derrocada política de Mbeki representa o ressurgimento político de Jacob Zuma, personagem central deste trabalho.

$\mathrm{Na}$ realização de pesquisas anteriores ${ }^{4}$ foi possível constatar que o CNA, que se apresentou como a maior força política de oposição ao apartheid durante quase cinco décadas, atualmente está envolvido em vários escândalos de corrupção. Em meados da década de 1960, devido à articulação política, a sigla tornou-se o alvo do Partido Nacionalista e do Estado branco. "O CNA foi destruído e todos os seus membros perseguidos" (JONGE, 1991, p. 63). Por mais que o partido tenha perdido representatividade entre os eleitores, ele se mantém no poder desde 1994. Entre a eleição de Mandela e 2018, dois presidentes deixaram o cargo, acusados de corrupção. Sobre o CNA, é importante frisar que:

A saída de Mandela da presidência marca o declínio do CNA. Com a ascensão de Mbeki e Zuma ao poder as acusações de corrupção e de abuso de poder passaram a ser frequentes. O partido se mantém no poder desde 1994, mas a cada pleito a vantagem sobre os adversários diminui. Consideramos que a sigla, em parte, permanece no poder graças à maioria numérica da população negra. Esta fidelidade ao partido pode ser motivada pelo passado de lutas e também pela influência de Nelson Mandela. Os escândalos de corrupção e má gestão estão entre as principais explicações de analistas sul-africanos para a queda de popularidade da sigla (SANTOS, 2014, p. 55).

\section{JACOB ZUMA E O LEGADO DA CORRUPÇÃO}

Em 14 de fevereiro de 2018, após sofrer pressões internas, o então presidente da África do Sul, Jacob Zuma, atendeu a uma deliberação interna do próprio partido político, o Congresso Nacional Africano (CNA) e renunciou de seu cargo. Eleito em 2009, com o apoio do

\footnotetext{
${ }^{4}$ Este artigo é um desdobramento da dissertação Iconografia e política na África do Sul: a representação de Nelson Mandela, Thabo Mbeki e Jacob Zuma nas charges de Zapiro, que foi apresentada e defendida junto ao Mestrado em Comunicação da Universidade Estadual de Londrina em 2014, sob orientação do Prof. Dr. Rozinaldo Antonio Miani. Renata de Paula dos Santos pesquisa a história sul-africana pós-apartheid desde 2010.
} 
ex-presidente Nelson Mandela, Zuma conseguiu se reeleger em 2014 e iria permanecer no cargo até 2019. Porém, com seu afastamento, o país passou a ser conduzido por Cyril Ramaphosa ${ }^{5}$.

O agora ex-presidente Jacob Zuma acumula mais de 800 denúncias de corrupção ${ }^{6}$, associada a uma vida particular conturbada. Além disso, existe a suspeita de que ele tenha usado a máquina pública para favorecer empresários em contratos de concessões públicas com o Estado. Entre as acusações, Zuma é suspeito de ter utilizado 246 milhões de rands ${ }^{7}$ (US\$ 15 milhões) em recursos públicos para a reforma de uma propriedade privada. Em 2016, ele começou a sofrer as primeiras pressões para renunciar, mas conseguiu permanecer no cargo até fevereiro de 2018. O relatório, intitulado "Estado de Captura", reuniria, de acordo com jornais sul-africanos, evidências de atos de corrupção em grande escala durante a gestão do líder zulu. Zuma nega todas as acusações.

Diante dos fatos mais recentes, tem ganhado cada vez menos destaque a informação de que Zuma foi militante no movimento de oposição ao apartheid. Ele se filiou ao CNA em 1958, aos 17 anos. Em 1962, Zuma passou a integrar o braço armado do partido, conhecido como Umkhonto we Sizwe (Lança da Nação). Em 1963, Zuma foi detido, acusado de tentar derrubar o governo branco. Ele permaneceu preso por dez anos na Ilha Robben, mesmo presídio onde esteve Nelson Mandela.

Quando deixou a prisão, em 1973, o líder negro continuou a lutar contra o regime de segregação racial. Em 1975, ele deixou a África do Sul e permaneceu no exílio por 15 anos, voltando ao país apenas quando Frederik de Klerk retirou os demais partidos políticos da ilegalidade. Entre 1990 e 1994, Zuma foi responsável por liderar as ações de paz entre o CNA e o Inkatha Freedom Party. Em 1994, quando Nelson Mandela foi eleito o primeiro presidente negro da África do Sul, Zuma assumiu cargos de liderança no CNA. Em 1999, ao término da gestão de Mandela, com a eleição de Thabo Mbeki, o político tornou-se vicepresidente da África do Sul (SANTOS, 2014).

A estreia de Zuma na vida pública já foi marcada por denúncias de corrupção. Em entrevista concedida aos autores deste artigo o cartunista Jonathan Shapiro, mais conhecido

\footnotetext{
${ }^{5}$ Cyril Ramaphosa destacou-se como um aliado histórico de Nelson Mandela, mas como não foi indicado para a sucessão presidencial abandonou a política e tornou-se um dos empresários mais bem sucedidos da África do Sul. O líder negro, também filiado ao CNA, foi eleito vice-presidente em 2014. Ele se apresentou, nos últimos meses da gestão de Zuma, como um dos principais críticos do ex-presidente.

${ }^{6}$ Cf. <https://brasil.elpais.com/brasil/2018/02/14/internacional/1518637991_462085.html>.

${ }^{7}$ Nome da moeda oficial da África do Sul.
} 
como Zapiro $^{8}$, que se apresenta como uma expressiva força de oposição ao político, destacou que ao ser indicado para a vice-presidência, Zuma já era alvo de acusações de corrupção.

Jacob Zuma era uma pessoa muito menos instruída e que parecia ser um [Thabo] Mbeki negociador, mas havia demostrado ter um péssimo senso de julgamento, moralidade e ética. Tudo isso era de domínio público, era evidente para quem quisesse ver, em 2002. Minha primeira charge sobre a corrupção de Zuma foi em 2002, cinco anos antes mesmo de o CNA nomeálo para ser o presidente do partido, mais de sete anos antes dele se tornar presidente do país. Para mim foi uma luta de 15 anos contra Jacob Zuma e uma luta de sete anos contra ele antes que chegasse à presidência (ZAPIRO, $2018)^{9}$.

Em 2005, quando exercia o cargo de vice-presidente, Zuma teve o mandato cassado pelo então presidente sul-africano, Thabo Mbeki, sob suspeita de corrupção. Ao contrário do que ocorre no Brasil, na África do Sul a cassação do mandato do vice-presidente é uma decisão do chefe de Estado (SANTOS, 2014). As denúncias contra Zuma foram retiradas em 2009, mas à época, a acusação era de que o político teria recebido o valor de U\$S 5 bilhões em um negócio de armamentos ${ }^{10}$. $\mathrm{O}$ então vice-presidente foi acusado de ter recebido suborno de seu assessor, Schabir Shaik, condenado pelas acusações de corrupção e fraude. Segundo Alexandra Fuller (2010), as suspeitas aumentaram a pressão popular para que Zuma fosse retirado do cargo, o que ocorreu em um prazo de duas semanas. No entanto, a cassação do mandato se apresentou mais como uma estratégia política de Mbeki, com a finalidade de melhorar os seus índices de popularidade, do que um combate efetivo à corrupção, já que ele também havia sido acusado de apropriação de recursos públicos.

A estratégia de Mbeki foi responsável por uma racha no CNA e não retirou Zuma da vida pública. Em 2007, Zuma venceu as eleições nacionais para a presidência do partido. Politicamente isolado, sem o apoio da sigla, Mbeki acabou renunciando ao cargo, abrindo espaço para a eleição de Zuma em 2009.

A vitória de Zuma [na eleição para a presidência do partido] resultou em uma perda de espaço de Mbeki. Além da falta de apoio da sigla, as acusações de corrupção também atingiram Thabo Mbeki, que renunciou ao cargo em 2008 por pressão do próprio CNA. A presidência foi ocupada,

\footnotetext{
${ }^{8}$ Zapiro é o autor de todas as charges analisadas neste artigo.

${ }^{9}$ Entrevista concedida pelo chargista aos autores deste trabalho. Tradução de Juliana Fontanella da Cunha e Carmem Caramori Fontes.

${ }^{10}$ De acordo com a Procuradoria Sul-Africana, Zuma será processado, acusado de corrupção. Segundo a Folha de S.Paulo, os desvios seriam da ordem de U\$S 2,5 bilhões, porém, em 2014, quando a dissertação de mestrado foi defendida, havíamos encontrado informações que afirmavam que o valor havia chegado a U\$S 5 bilhões.
} 
interinamente, por Kgalema Motkanthe. Para McGreal (2008), Mbeki foi derrubado pelos escândalos da AIDS e da corrupção. A renúncia derivada da pressão partidária legitimou o racha no CNA. Apoiadores de Mbeki deixaram a sigla e formaram o Congresso do Povo (Cope), um novo partido que alcançou o terceiro lugar nas eleições de 2009. A renúncia do líder negro culminou no seu afastamento do alto escalão político sul-africano (SANTOS, 2014, p. 50-51).

\section{A CARACTERIZAÇÃO DO PERSONAGEM CORRUPTO NO TRAÇO DE ZAPIRO}

Neste tópico serão analisadas algumas charges produzidas por Jonathan Shapiro. Mais conhecido como Zapiro, ele é apontado como um dos chargistas mais influentes da África do Sul. Ao longo desta reflexão, a charge será concebida como um texto ideológico com a possibilidade de tensionar a realidade política em que está inserida. Essa modalidade do humor gráfico age como um meio informativo, já que traz características de um fato, e exerce também a função de uma ferramenta de luta política, uma vez que se destina ao debate das ideologias (SANTOS, 2014).

Para Rozinaldo Miani (2005), a charge possui um caráter eminentemente político e que não se desvencilha do humor. O seu argumento possui características críticas e é elaborado a partir da crítica a um fato ou a um indivíduo específico e na defesa de uma ideia. Ainda para o referido autor, a charge é um instrumento de crítica que auxilia no debate ideológico e na organização política da sociedade. Como manifestação linguística, o texto é compreendido como um instrumento de persuasão (MIANI, 2012). Diante destas características, considera-se que a análise do discurso chárgico se apresenta como a metodologia mais apropriada para a condução das análises.

Em janeiro de 2018, prestes a deixar o comando do país, os principais veículos de comunicação da África do Sul publicaram que o então presidente, Jacob Zuma, havia apresentado às lideranças do CNA uma lista com as exigências dele para deixar o cargo. O objetivo do presidente era ditar quais seriam as principais articulações políticas após sua saída.

A primeira charge selecionada, intitulada Calling the shots (Chamando os Tiros), remonta ao repertório cultural ao representar o então presidente enquanto um prisioneiro em um navio pirata (figura 01). Zuma está encurralado, na prancha, entre os possíveis tiros que serão disparados pelo inimigo (também há facões!) e os tubarões que estão em volta do navio. A ironia do argumento é estabelecida na fala atribuída ao personagem: “...Oh al right then! Here are my term and conditions!...” (“...Ah tudo bem então! Aqui estão meus termos e condiçôes!...”). O que Zapiro procurou expressar, de maneira irônica, é justamente o 
contrário, pois Zuma não tinha condições de fazer nenhuma exigência ao CNA, devido ao isolamento político, fruto da instabilidade que ele mesmo havia provocado.

\section{Figura 01}

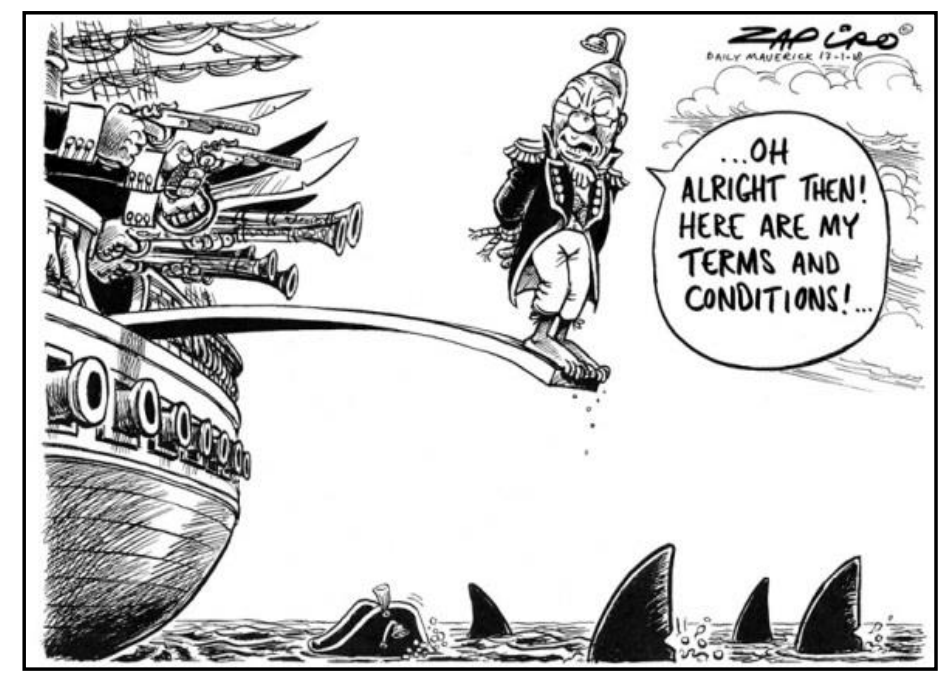

Fonte: Calling the shots, Zapiro, $2018^{11}$

Na figura seguinte aparece, certamente, o argumento mais ligado às acusações de corrupção envolvendo o então presidente (figura 02). Zuma é acusado de ter favorecido a família Gupta, milionários influentes no país, que operam uma mina de urânio na África do Sul. Os três irmãos têm o poder para ditar regras no interior do CNA, bem como para indicar nomes para ocupar cargos importantes na administração pública.

Figura 02

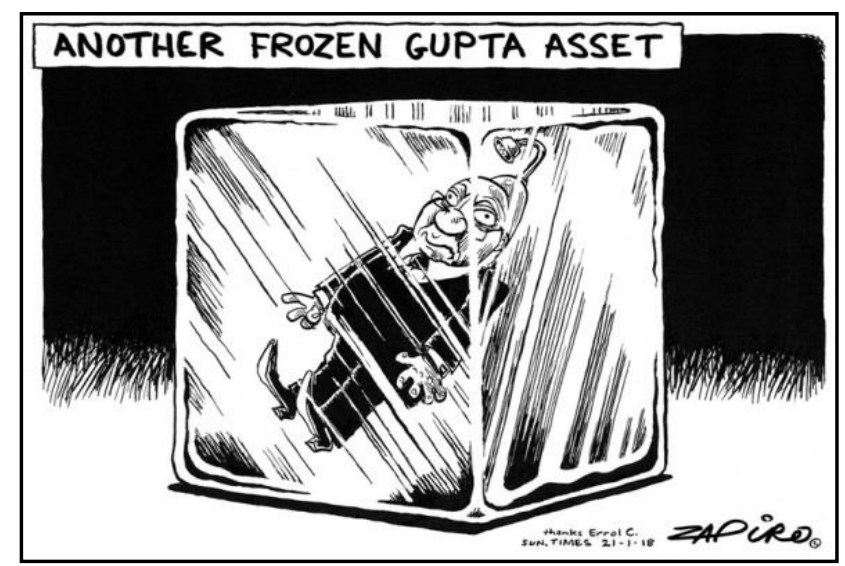

Fonte: Another Frozen Gupta Asset, Zapiro, $2018^{12}$

\footnotetext{
11 C 1994-2018 Zapiro (All rights reserved) Republished with permission from <www.zapiro.com>. For more Zapiro cartoons visit <www.zapiro.com>.
} 
O título da charge Another Frozen Gupta Asset (Outro Ativo Gupta Congelado) é uma ironia do chargista a uma operação iniciada pela Unidade de Confisco de Ativos, com a finalidade de recuperar cerca de 1,6 bilhões de rands desviados, possivelmente em esquemas com a participação dos irmãos. Além de considerar que 17 ações vinculadas à referida operação - que estão sob análise - não representariam o retorno de dinheiro aos cofres públicos, Zapiro aponta também para o congelamento dos fatos ilícitos que supostamente poderiam envolver o ex-presidente. A metáfora utilizada pelo chargista para criticar o "congelamento" das investigações foi mostrar Zuma dentro de um bloco de gelo.

Em fevereiro de 2018, diante do agravamento da crise e às vésperas de sua queda, lideranças políticas cobraram que a renúncia de Zuma acontecesse antes do discurso sobre o Estado-Nação, evento tradicional realizado no Parlamento, com a presença de representantes de todos os partidos. Como não foi possível, lideranças políticas solicitaram a Zuma que o evento fosse adiado, com receio da reação popular. Zuma atendeu ao pedido, que foi tematizado por Zapiro em uma de suas charges (figura 03).

\section{Figura 03}

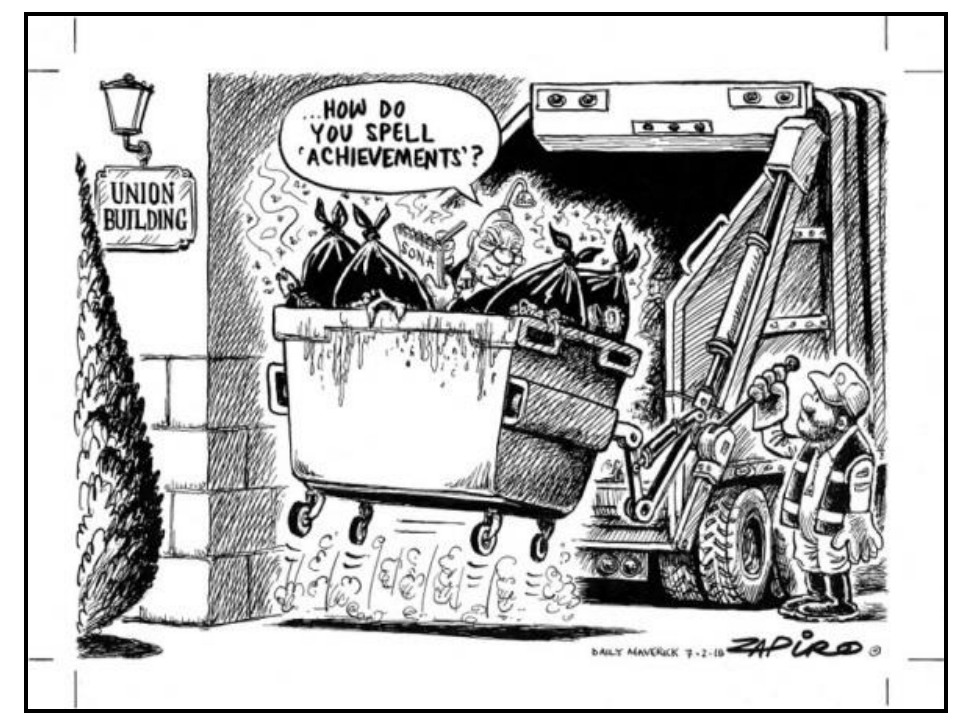

Fonte: Sona Shift, Zapiro, $2018^{13}$

Nessa charge, intitulada pelo próprio chargista de Sona Shit (Discurso Sobre o Estado Nação Mudado), há uma transgressão na representação das condições formais de um

\footnotetext{
12 (C) 1994-2018 Zapiro (All rights reserved) Republished with permission from <www.zapiro.com>. For more Zapiro cartoons visit <www.zapiro.com>.

13 (C) 1994-2018 Zapiro (All rights reserved) Republished with permission from <www.zapiro.com>. For more Zapiro cartoons visit <www.zapiro.com>.
} 
presidente da República. Zuma aparece em uma espécie de caçamba, destinada ao recolhimento de entulhos e rejeitos. Esta interpretação é reforçada pela presença de um caminhão coletor sendo operado por um homem uniformizado (representando um coletor de lixo) e também pelos sacos de lixo que completam o conteúdo da caçamba. Este cenário é revelador da crítica feita pelo chargista à gestão de Zuma. Como o argumento aponta para o discurso que ele deveria fazer no Parlamento, Zuma aparece pedindo sugestões. Ao questionar, how do you spell 'achievements'? (como você soletra 'conquistas'?), o que fica problematizada é a avaliação negativa atribuída pelo chargista à gestão do líder zulu.

\section{JACOB ZUMA E AS POLÊMICAS PESSOAIS}

Além das controvérsias políticas, Jacob Zuma também ocupou as páginas dos jornais em razão de escândalos envolvendo questões pessoais. O ex-presidente, pertencente à etnia $z u l u$, é adepto da poligamia, prática que é permitida na África do Sul. Zuma se casou seis vezes e, atualmente, tem quatro esposas. Ele ficou viúvo de uma de suas mulheres e se divorciou de outra. O político sempre foi criticado por organizações sociais sul-africanas pela poligamia, principalmente, considerando as graves estatísticas da AIDS no país. O discurso foi de que o ex-presidente, por ter múltiplas parceiras, depunha contra as campanhas de conscientização. Segundo Santos (2014), a transmissão do vírus tornou-se um dos principais problemas do país após o regime de segregação racial. A África do Sul sofre com uma epidemia da doença e, aproximadamente, $17 \%$ dos portadores do HIV em todo o planeta residem em território sul-africano. Devido à epidemia, a expectativa de vida, que na década de 1960 era de 58,3 anos, caiu para 48,9 anos em 2010.

Jacob Zuma também é acusado de ter mandado matar um suposto amante de uma das suas esposas. Em fevereiro de 2010, menos de um ano após ter chegado à Presidência da África do Sul, o líder zulu assumiu a paternidade de uma criança concebida fora dos seus quatro casamentos. A mãe da criança era a chefe do comitê organizador da Copa do Mundo da África do Sul.

Porém, o ponto alto das polêmicas envolvendo Zuma aconteceu em 2006, quando uma jovem apontada como filha de um dos seus amigos o acusou de tê-la estuprado. A suposta vítima é portadora do vírus da AIDS. A denúncia foi levada aos tribunais, mas culminou na declaração de inocência do político. O processo de julgamento foi uma etapa necessária para que o líder negro pudesse se apresentar como candidato pelo CNA. Na África do Sul, pessoas 
com pendências judiciais não podem disputar eleições. Durante o julgamento, Zuma afirmou que manteve relações sexuais com a jovem, mas que o ato foi consensual. Já a suposta vítima classificou o episódio como uma "violência horrível".

\section{ESTUPRO, ZUMA SHOWER E A VALORIZAÇÃO DA REPRESENTAÇÃO FÁLICA}

Zapiro se apresentou como um crítico ferrenho das gestões da Thabo Mbeki e, principalmente, de Jacob Zuma. Em uma entrevista concedida ao portal G1, em 2009, ele informou que o seu trabalho ganhou um caráter mais político ao término do governo de Mandela, pela chegada de Mbeki ao poder e pelo aumento nas acusações de corrupção.

O meu ponto de vista é altamente crítico em relação à política do país. Os políticos que estão no poder têm uma atuação intolerável diante de muitas questões como corrupção e sexualidade. [...] Eu ouço e vejo muitos erros dentro do país. A minha grande motivação para produzir sobre os absurdos que acontecem é persistir em uma mudança (ZAPIRO apud LUZ, 2009).

O chargista sul-africano tem sido muito criticado por representantes do governo pelos argumentos que apresenta nas charges, mas a relação mais desgastada se estabeleceu justamente com Jacob Zuma. A acusação de estupro tem sido uma temática frequente no trabalho de Zapiro, por mais que o processo contra o ex-presidente tenha sido arquivado em 2009 por falta de provas.

$\mathrm{Na}$ própria caricatura de Zuma, Zapiro passou a explicitar a materialização da acusação de estupro ao acrescentar um chuveiro sobre a cabeça do personagem, o que foi chamado pelo chargista de Zuma Shower (figura 04), como pode ser percebido na charge Aids Message (Mensagem da Aids). 


\section{Figura 04}

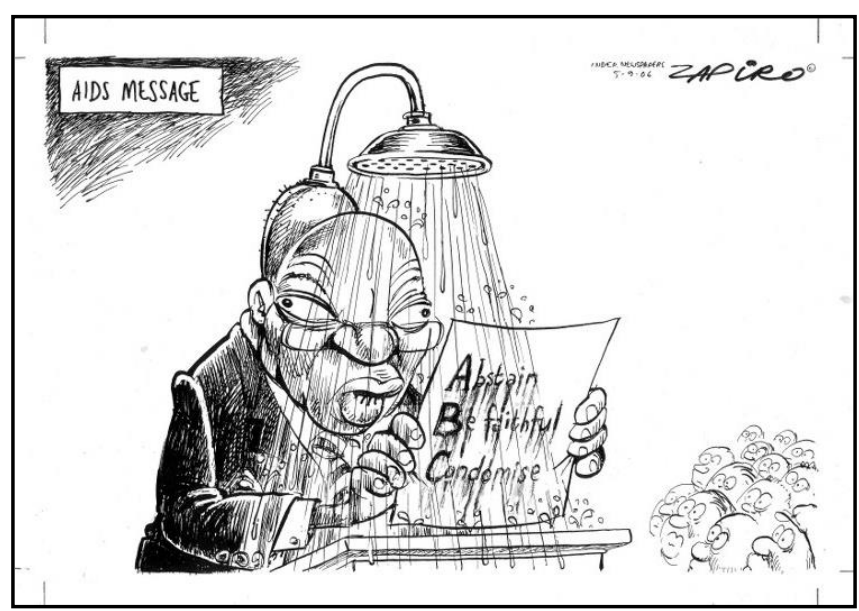

Fonte: Aids Message, Zapiro, $2006^{14}$

O Zuma Shower ganhou ainda mais repercussão e se validou enquanto elemento gráfico, principalmente, após o julgamento do caso da denúncia de estupro. Embora Zuma tenha reiterado que a relação sexual foi consensual, ele reconheceu que a jovem em questão era portadora do HIV, que ele não usou preservativo e que para evitar a sua própria contaminação ele teria "tomado um banho". Discursivamente, a declaração assumiu uma representação ainda mais negativa pelas funções políticas que Zuma já havia assumido até então. Em entrevista aos autores deste trabalho, ainda sobre o Zuma Shower, Zapiro afirmou:

Começou como algo simples durante a primeira acusação de corrupção de Jacob Zuma e ficou muito maior. É claro que continuou e continuou durante o período em que ele foi acusado de estupro. O julgamento aconteceu em 2006 e ele foi absolvido, mas durante o interrogatório ele disse que embora conhecesse a mulher com quem fez sexo, nas palavras dele: sexo consensual. Nas palavras dele, certo? Ele sabia que ela era soropositiva e quando the perguntaram no interrogatório "o que você fez depois de fazer sexo", ele disse que havia tomado um banho. Quando lhe questionaram a razão, ele disse que foi para diminuir a chance de uma infecção. Jacob Zuma havia sido o chefe do programa nacional de AIDS quando era vice-presidente, então ele dizer que ele tomou banho para diminuir sua chance de infecção foi ridículo. Por isso, quando ele foi absolvido, eu fiz uma charge onde eu fazia representações físicas de coisas que ele tinha dito, de suas atitudes, e adicionei essas coisas ao seu corpo. Por exemplo, uma metralhadora, da qual ele falou. Eu desenhei essa metralhadora atirando espermatozóides no formato de sua cabeça, uma arma com visor e mira para as saias curtas, porque ele disse que a mulher estava usando uma saia curta insinuante e, para ele, isso queria dizer que ela o estava convidando para fazer sexo. Esse foi o tipo de comentário que ele fez. Então, entre esses outros comentários,

14 @ $1994-2018$ Zapiro (All rights reserved) Republished with permission from <www.zapiro.com>. For more Zapiro cartoons visit <www.zapiro.com>. 
entre essas representações físicas, eu coloquei um chuveiro na cabeça dele que dizia "para a prevenção da AIDS" (ZAPIRO, 2018) $)^{15}$.

Esta charge é de 2006 e corresponde a um período em que Zuma estava sem cargos públicos na África do Sul. Ele havia perdido o mandato como vice-presidente do país, ainda não havia assumido a direção nacional do CNA e também não havia sido eleito presidente da República, o que só aconteceu em 2009.

Nesta imagem, que sintetiza bem o conceito de charge como um texto visual de caráter humorístico que estabelece uma crítica a um personagem, fato ou acontecimento político (ROMUALDO, 2000), Zapiro remete, justamente, ao fato de que Zuma, por ter alegado que o ato sexual foi consensual, não utilizou preservativo e que, após o fato, ele teria tomado um banho para evitar a contaminação.

A representação gráfica simula um pronunciamento de Zuma. O político aparece em um púlpito, supostamente diante de um público, segurando um papel que, provavelmente, trazia o discurso a ser proferido; no verso do documento, podemos ler as palavras abstain (evitar), be faithful (ser fiel) e condomise (camisinha/preservativo). Com isso, o chargista está reforçando a informação de que esses são os três princípios básicos para evitar a disseminação da AIDS; não sem intenção, eles começam com as letras ABC, como uma espécie de princípio básico de alfabetização para a prevenção da doença. Porém, tais palavras estão sendo manchadas e apagadas pela água lançada pelo chuveiro sobre a cabeça de Zuma, numa crítica à sua conduta no episódio em questão e também à repercussão de tal conduta, uma vez que ele havia chefiado, justamente, o programa nacional de AIDS quando ocupava a vicepresidência do país.

As caricaturas (retrato caricato) são elementos constituintes das charges (ROMUALDO, 2000; MIANI, 2005) possibilitando que os leitores reconheçam os personagens que estão representados, e assim, reconheçam os fatos retratados. Nesse sentido, o recurso do Zuma Shower passou a ser utilizado por Zapiro para a representação do político em todas as suas retratações envolvendo as denúncias de corrupção de seu governo.

As próximas charges analisadas também tomam como base o episódio do estupro. A charge intitulada The Rape of Justice (A violação da Justiça) foi considerada pelo site especializado em humor gráfico, Africartoons, como a charge mais genial já produzida na África do Sul (figura 05). O argumento motivou que o político processasse Zapiro e também o jornal Sunday Times, onde ela foi originalmente publicada.

\footnotetext{
${ }^{15}$ Tradução de Juliana Fontanella da Cunha e Carmem Caramori Fontes. 


\section{Figura 05}

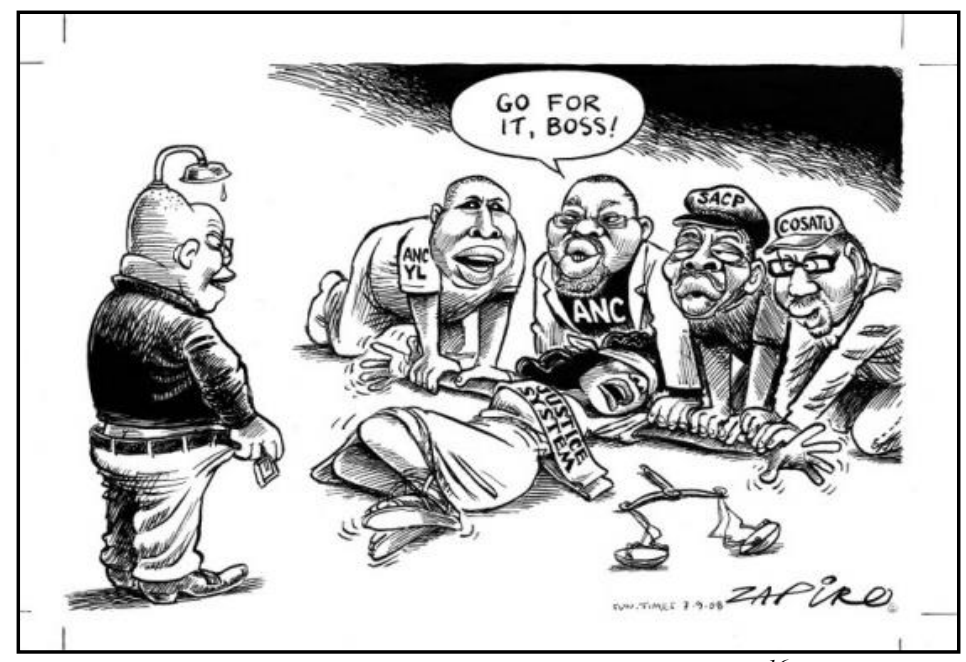

Fonte: The Rape of Justice, Zapiro, $2008^{16}$

The Rape of Justice foi interpretada pelo CNA e pelo então presidente Jacob Zuma como um argumento com conotação racista. Já a opinião pública sul-africana considerou que o fato se apresentou como um atentado à liberdade de expressão. Vários chargistas, em solidariedade a Zapiro, começaram a produzir charges com argumentos semelhantes ao que o referido chargista havia utilizado.

Entre as inúmeras interpretações possíveis advindas desta charge, podemos considerar que a crítica pretendida era de alertar para o fato de que Zuma estaria prestes a violentar o sistema judiciário sul-africano; para isso, ele contava com o apoio de alguns de seus aliados políticos ${ }^{17}$. Para aumentar a dramaticidade e permitir uma alusão maior à acusação de estupro pela qual o político ainda respondia (a charge é de setembro de 2008 e a ação foi arquivada apenas no ano seguinte), Zapiro "deu vida" ao sistema judiciário sul-africano, representando-o como uma mulher. Por mais que a figura seja alegórica, a cena não deixa de provocar um choque no leitor.

Quando a charge foi publicada, Zuma já era presidente do CNA e estava com a candidatura à Presidência do país praticamente assegurada. $\mathrm{O}$ chargista tentou problematizar a influência exercida pelo político e também pelos aliados sobre a Justiça sul-africana. É preciso lembrar que, se o líder negro não tivesse sido inocentado naquele julgamento em

\footnotetext{
16 (C) 1994-2018 Zapiro (All rights reserved) Republished with permission from <www.zapiro.com>. For more Zapiro cartoons visit <www.zapiro.com>.

17 Os aliados políticos presentes na figura são Julius Malema (representante da Liga Jovem do CNA, braço armado do partido), Gwede Mantashe (secretário-geral do CNA), Blade Nzimande (candidato à vice-presidência; membro do Partido Comunista Sul-Africano) e Zwelinzima Vavi (secretário-geral do Congresso dos Sindicatos Sul-Africanos). A presença destes homens na charge reforça a crítica ao sistema político sul-africano e, principalmente, ao CNA e aos partidos que apóiam o governo.
} 
questão, ele não poderia ter concorrido às eleições. A crítica não se efetiva apenas contra o CNA, mas também contra os demais partidos que compõem a base aliada, já que havia uma cumplicidade entre eles e Jacob Zuma. Na imagem, enquanto o então pré-candidato à Presidência realiza o movimento de se despir - abrindo o zíper da calça -, o grupo segura a mulher e incentiva a violência a partir da frase: "vá em frente, chefe" ("Go for it, boss").

The Rape of Justice ganhou destaque na África do Sul e em importantes jornais internacionais, como o The Times. Em entrevistas, o chargista afirmou que chegou a considerar a possibilidade de não publicar esta charge, não em razão de algum tipo de represália de Zuma ou mesmo do CNA, mas por receio de ofender as mulheres que já foram vítimas de violência sexual. O sucesso da crítica realizada por Zapiro foi tão significativo entre outros chargistas, e também com a opinião pública, que o mesmo argumento foi adaptado para outras ocasiões. Esse tipo de situação reforça a natureza intertextual da charge (ROMUALDO, 2000; MIANI, 2005), estabelecendo entre as imagens um diálogo que é operado pelo leitor, este que deve ser conhecedor das diferentes charges.

Em pelo menos duas das charges que retomam a situação da acusação de estupro, Zapiro recria no universo chárgico o paradigma da violência sexual, ainda que, cronologicamente, o fato não estivesse mais na memória social sul-africana. Nessas figuras, o chargista apresenta os mesmos personagens e em um mesmo cenário. Na primeira delas, a diferença se estabelece apenas na fala que o chargista atribui a Jacob Zuma (figura 06). Muito provavelmente, a charge foi publicada após alguma manifestação do político sul-africano contra a primeira imagem.

Publicada originalmente sem título, podemos considerar essa charge uma continuidade de The Rape of Justice. Os aliados políticos permanecem segurando a mulher, mas estão com os olhos fechados, talvez em uma condição solene, enquanto Zuma afirma: “...mas antes de começarmos, eu quero dizer como nós respeitamos você" (...but before we start, I Just want to say how much were spect you). Porém, a justificativa simbólica agrava ainda mais a situação, considerando que o argumento no caso toma como base um estupro e faz referência a possíveis manobras realizadas pelo político para conseguir ser candidato à Presidência. 


\section{Figura 06}

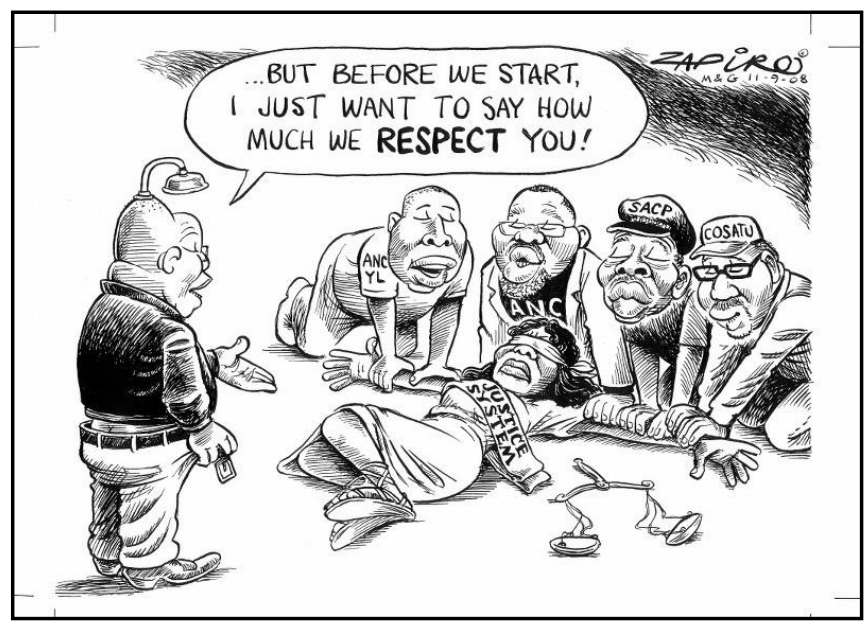

Fonte: Sem título, Zapiro, $2008^{18}$

A outra charge, The Rape of Free Speech (A violação da Liberdade de Expressão), foi publicada por Zapiro em 11 de junho de 2011 (figura 07), cinco após o suposto estupro. Essa charge já é uma representação de Zuma como presidente da República.

\section{Figura 07}

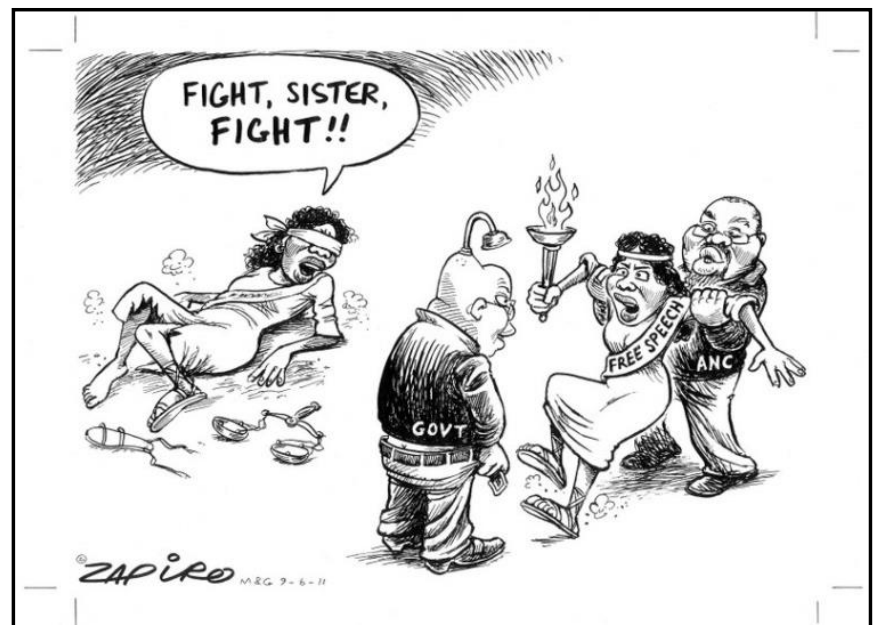

Fonte: The Rape of Free Speech, Zapiro, $2011^{19}$

$\mathrm{O}$ argumento, mais uma vez, é similar ao The Rape of Justice e traz implícita a ideia do estupro. Gwede Mantashe, então secretário-geral do CNA - também presente na figura original -, segura a mulher que representa a "liberdade de expressão" enquanto Jacob Zuma,

18 C $1994-2018$ Zapiro (All rights reserved) Republished with permission from <www.zapiro.com>. For more Zapiro cartoons visit <www.zapiro.com>.

19 (C) 1994-2018 Zapiro (All rights reserved) Republished with permission from <www.zapiro.com>. For more Zapiro cartoons visit <www.zapiro.com>. 
mais uma vez, aparece tirando as calças e abrindo o cinto, numa clara atitude de quem pretende cometer violência sexual. Ao lado dessa cena, a (mesma) mulher que representou a Justiça na charge anterior e que havia sido violentada aparece gritando "Lute, irmã, lute!!" ("Fight, sister, fight!!"). A condição desta mulher é de quem efetivamente havia sido agredida, estando estirada no chão sem condições de reação diante da (nova) situação de violência que se anunciava.

Esta charge é mais uma crítica explícita do chargista ao líder sul-africano. Após afirmar que o político havia manipulado o sistema judiciário, quando ainda disputava internamente no CNA a indicação para ser o candidato à Presidência, Zapiro criticava agora as tentativas de Zuma de controlar os meios de comunicação. Diante da charge, o CNA chegou a cogitar a possibilidade de mover um novo processo contra Zapiro.

As críticas do CNA não foram suficientes para que o chargista deixasse de explorar intertextualmente a charge The Rape of Justice. Em 2012, quando o então presidente retirou uma das ações que movia na Justiça contra Zapiro, o chargista respondeu com outra charge (figura 08). Zapiro se utilizou, mais uma vez, de seu argumento original, mas, desta vez, Zuma foi a "vítima". Essa charge pode ser interpretada como um acerto de contas de Zapiro com o presidente.

\section{Figura 08}

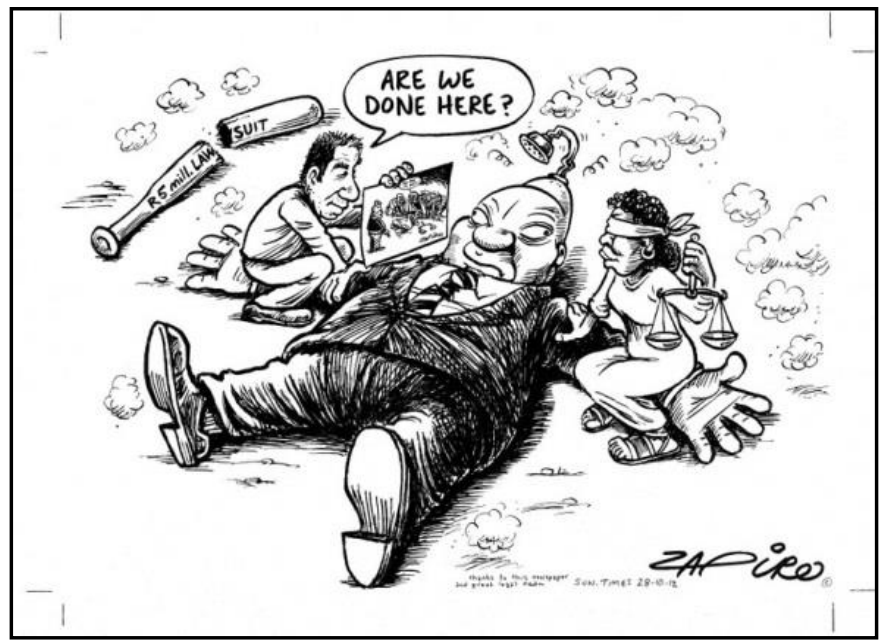

Fonte: Sem título, Zapiro, $2012^{20}$

Nesta charge, o próprio Zapiro está presente na representação. Ele mostra ao político a polêmica charge The Rape of Justice que motivou todo o embate entre as duas partes. A

\footnotetext{
20 ๑) 1994-2018 Zapiro (All rights reserved) Republished with permission from <www.zapiro.com>. For more Zapiro cartoons visit <www.zapiro.com>.
} 
mulher que representa a Justiça também aparece e, juntamente com o chargista, imobilizam Zuma no chão. A pergunta do chargista é irônica: Are we done here? (“Terminamos aqui?") e representa uma crítica ferrenha ao presidente, já que uma das maiores conquistas da África do Sul pós-apartheid passa, justamente, pelas garantias de liberdade de expressão presentes na nova Constituição.

Para encerrar a abordagem da vida pessoal do ex-presidente sul-africano, destaca-se a charge Twin Showers (Chuveiros Gêmeos). A charge foi produzida após uma exposição, realizada em 2012, com obras do artista Brett Murray. Identificando-se como partidário antiapartheid durante o regime de segregação racial e ex-militante do CNA, o referido artista já havia organizado uma exposição em que satirizava os líderes racistas do regime de segregação. Porém, a mostra gerou polêmica a partir da análise do centenário do CNA, ao lado de temas como a corrupção e o nepotismo. A obra "A Lança" (figura 09) foi a que causou mais polêmica. O líder zulu foi representado como um fac-símile de um famoso cartaz do revolucionário comunista russo Vladimir Lenin, porém a representação assume um caráter irônico, já que a genitália do político está exposta.

\section{Figura 09}
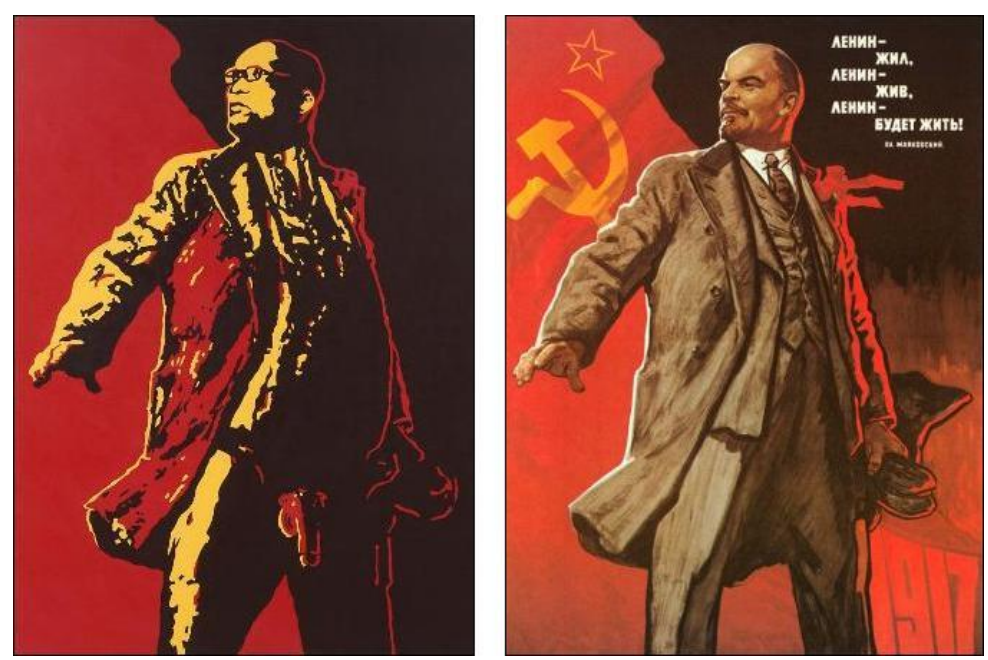

Fonte: Obra "A Lança”, de Brett Murray, 2012, e cartaz original Vladimir Lenin

Fazendo uma paródia da obra de Brett Murray, Zapiro produz uma charge explorando, mais uma vez, o Zuma Shower (figura 10). Ironicamente, Zapiro opta pela representação de dois chuveiros: o primeiro, no topo da cabeça, e o segundo, representando o órgão genital do político. A charge não só estabelece uma intertextualidade com a obra de Murray, como 
também retoma as polêmicas pessoais do político, desta vez não a partir do episódio do estupro, mas da poligamia e da infidelidade.

Figura 10

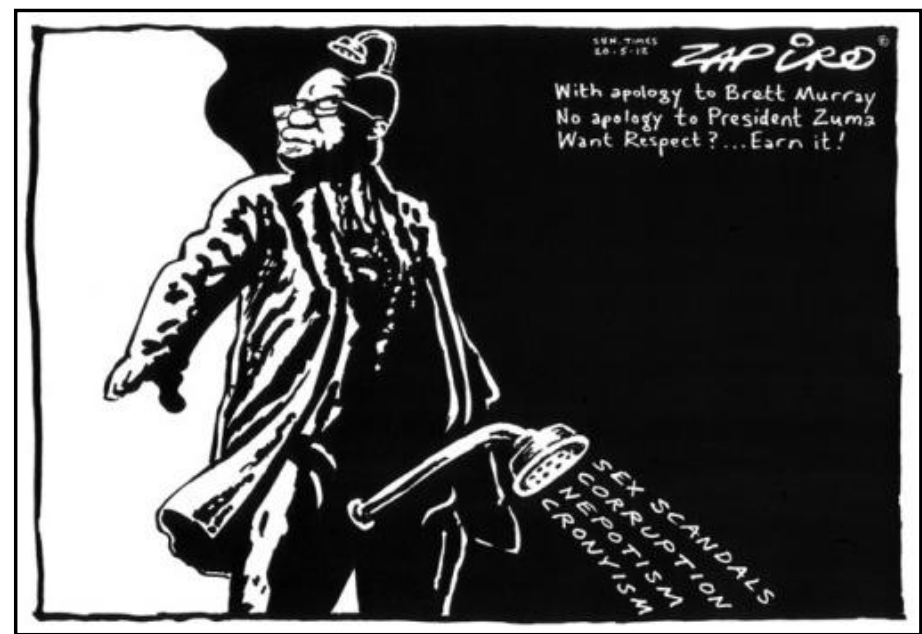

Fonte: Twin Showers, Zapiro, $2012^{21}$

A ligação entre a charge e a obra "A Lança" é explicitada pelo próprio Zapiro ao afirmar que o argumento foi constituído "with apology to Brett Murray. No apology to President Zuma. Want Respect? Earn it”. ("Em defesa a Brett Murray. Nenhuma desculpa ao Presidente Zuma. Quer respeito? Ganhe-o”). No segundo chuveiro, que tem a finalidade de substituir a genitália originalmente exposta no trabalho de Murray, "escorrem" algumas das acusações que foram atribuídas ao então presidente sul-africano: escândalos sexuais (sex scandals), corrupção (corruption), nepotismo (nepotism) e clientelismo (cronyism). De acordo com Santos (2014), a charge em questão foi bem recebida pelo público que a elegeu entre uma das dez mais populares de Zapiro em 2012.

\section{AUTOMATIZAÇÃO DO ZUMA SHOWER COMO INDICATIVO DO PERSONAGEM}

Desde 2006, o Zuma Shower tem se tornado um elemento gráfico bastante representativo para a apresentação caricata do líder zulu no traço de Zapiro. Em uma entrevista concedida à jornalista Natália Luz, em 2009, o chargista afirmou que logo após a publicação da primeira caricatura do político com o chuveiro, ele foi processado. Zapiro

\footnotetext{
21 (C) 1994-2018 Zapiro (All rights reserved) Republished with permission from <www.zapiro.com>. For more Zapiro cartoons visit <www.zapiro.com>.
} 
declarou: "Ele disse que ia me processar em 15 milhões de rands ${ }^{22}$ por eu manchar a reputação dele. Ficou tão furioso que dizia isso em entrevistas e para toda imprensa. Falava que eu o chamava de corrupto e estuprador" (ZAPIRO apud LUZ, 2009).

Em entrevista concedida aos autores deste artigo, Zapiro destacou que não esperava a repercussão alcançada pelo Zuma Shower. De acordo com o chargista, o público chegou a cobrá-lo pela ausência do elemento gráfico, antes dele se tornar fixo nas representações do líder zulu. A esse respeito Zapiro declarou:

O desenho seguinte que eu fiz não tinha mais essas representações físicas porque elas realmente funcionaram naquele desenho, mas aconteceu uma coisa que eu realmente achei engraçado, várias pessoas vieram me perguntar "onde está o chuveiro"? De tantas coisas que eu coloquei na charge, elas sentiram a ausência do chuveiro em Zuma. Então eu pensei, "bem, isso é algo que eu realmente posso continuar fazendo", e é por isso que eu coloquei de volta na cabeça dele e ali ficou. $O$ efeito da representação se tornou realmente enorme porque as pessoas começaram a me acusar de chamá-lo de estuprador o tempo todo, porque eu coloquei o chuveiro na cabeça [de Zuma]. Eu disse, mas "isso não é sobre o estupro, é sobre o HIV". Então eles começaram a dizer "você não pode fazer isso porque é indigno", "você não pode fazer isso com alguém que está tentando se tornar presidente", eu achei muito engraçado (ZAPIRO, 2018) ${ }^{23}$.

Em fevereiro de 2018, quando a pressão do CNA se tornou mais intensa para que Zuma renunciasse ao cargo, Zapiro "experimentou" praticar o "minimalismo" para a representação gráfica de Zuma, a partir da automatização do Zuma Shower. Ou seja, o chargista chegou a apresentar apenas o chuveiro como indicativo do presidente. No entanto, a compreensão da mensagem só era possível para os leitores que acompanhavam regularmente as charges de Zapiro.

Como mencionado anteriormente, as caricaturas - que também são uma modalidade do humor gráfico - estão presentes na charge, principalmente, com o objetivo de que todos os leitores reconheçam o contexto representado. Edson Carlos Romualdo (2000) considera que a caricatura é um recurso gráfico que exagera, intencionalmente, as características mais marcantes do indivíduo e está bastante ligada à representação de lideranças políticas, porém o argumento só é válido se o leitor reconhece os personagens, ou seja, "se isso não acontece, o seu sentido se esvai” (ROMUALDO, 2000, p. 25). No caso de Zapiro, sua obra é amplamente difundida e conhecida na África do Sul, além do que, Jacob Zuma foi o presidente do país por

\footnotetext{
${ }^{22}$ Cerca de US\$ 1,2 milhão.

${ }^{23}$ Tradução de Juliana Fontanella da Cunha e Carmem Caramori Fontes.
} 
quase nove anos (de maio de 2009 até fevereiro de 2018); portanto, a sua "experimentação" certamente foi bem sucedida.

No dia 11 de fevereiro de 2018, quando o Comitê Executivo Nacional do CNA estava às vésperas de se reunir para decidir o futuro do presidente Zuma, Zapiro publicou a charge intitulada Questão de tempo (Question When) (figura 11). Nessa charge ainda foi utilizada a figura de Zuma, porém numa proporção reduzida em relação à retratação feita até então. Num fundo preto, a caricatura do (ainda) presidente aparece pequena e, acima de sua cabeça, vemos um grande chuveiro, em referência ao Zuma Shower. A imagem forma um "ponto de interrogação", em referência ao contexto de indefinição da situação de Zuma.

Figura 11

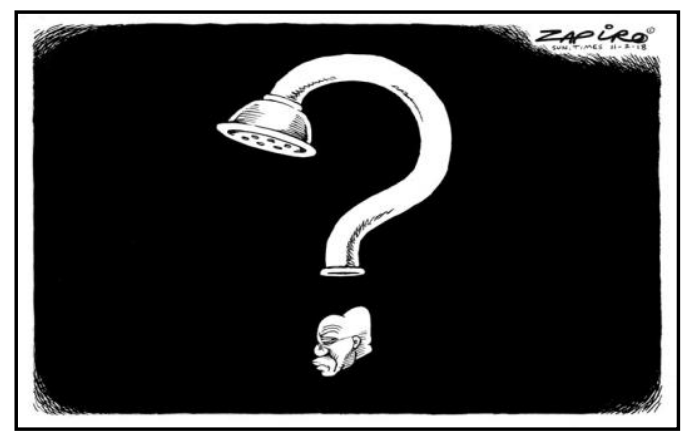

Fonte: Question When, Zapiro, $2018^{24}$

Por sua vez, em charge publicada no dia 15 de fevereiro de 2018, um dia após o líder zulu ter atendido às deliberações do partido e ter renunciado à presidência sul-africana, Zapiro produziu a charge $O$ Fim (The End) (figura 12).

Figura 12

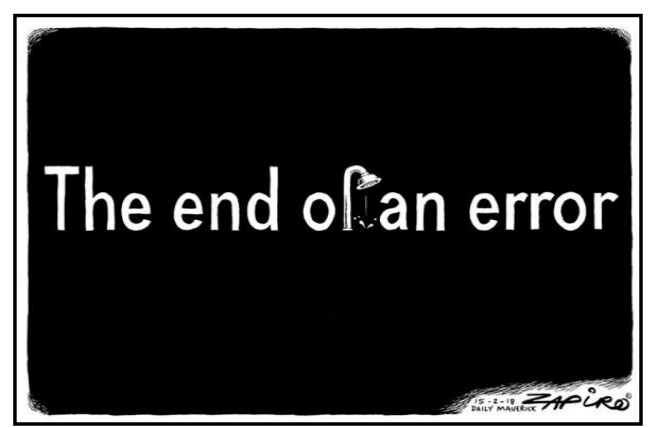

Fonte: The end of an error, Zapiro, $2018^{25}$

\footnotetext{
24 (C) 1994-2018 Zapiro (All rights reserved) Republished with permission from <www.zapiro.com>. For more Zapiro cartoons visit <www.zapiro.com>.

25 (C) 1994-2018 Zapiro (All rights reserved) Republished with permission from <www.zapiro.com>. For more Zapiro cartoons visit <www.zapiro.com>.
} 
Nesta charge não há a presença de Jacob Zuma. A mensagem é transmitida apenas pelo texto. A referência ao político se apresenta a partir do chuveiro, que representa a letra "f”. Por mais que Zapiro não tenha feito nenhuma referência explícita ao representante político ao escrever The end of an error ( $O$ fim de um erro), é sabido que a charge trata da renúncia de Zuma e que ele está representado pelo chuveiro. Além disso, nessa frase, o chargista sintetizou a sua opinião de como foram os nove anos da administração do líder zulu.

Como podemos verificar, um elemento que inicialmente tinha a finalidade de compor uma única charge tornou-se uma ferramenta com características próprias, com a capacidade de sintetizar um presidente da República. E essa decisão foi motivada, dentre outras razões, pela adesão do público, portanto, uma construção ideológica derivada da cumplicidade entre o chargista e seu público. A respeito da natureza da charge como produto ideológico, Luciana Coutinho de Souza e Maria Ogécia Drigo afirmam:

A charge, como produto ideológico que é, apresenta a dupla face do signo. Através da materialidade significante - grafismo, texto verbal, traço humorístico - virá à tona essa duplicidade: ao refletir a realidade, a charge compactua com o sistema, assumindo a força do discurso competente - o discurso cuja linguagem é institucionalmente permitida ou autorizada; ao refratar a realidade, ela deixa escapar as fissuras da dominação. Ou seja, ao deformar, a caricatura aponta para outro discurso, para outro signo, para outra linguagem. É na deformação do referente original que existe o desvio revelador do aspecto ideológico. É nesse desvio que o signo, ao refletir, quebra a direção e transforma, transfigura, refrata a realidade (DRIGO; SOUZA, 2006).

\section{CONSIDERAÇÕES FINAIS}

O trabalho de Zapiro possibilita que se perceba a charge a partir de uma dupla condição: inicialmente, como um produto comunicativo - veiculado periodicamente nas páginas de jornal - em que informações e análises sobre fatos sociais e personalidades do cotidiano são apresentadas; e, posteriormente, como fonte de pesquisa histórica - processo que se efetivou para essa pesquisa - a partir da análise do discurso chárgico. Neste artigo foi possível evidenciar, por meio das charges, informações essenciais para compreender o complexo processo democrático sul-africano pós-apartheid.

Desde a eleição de Nelson Mandela, em 1994, os sul-africanos têm escolhido líderes negros e com passado de militância contra o regime de segregação racial. No entanto, o CNA, que se efetivou como uma das mais representativas forças de oposição do país durante o 
apartheid, tem se transformado, com o passar dos anos, em um partido menos popular e marcado pelas frequentes acusações de corrupção.

Jacob Zuma, eleito em 2009 e reeleito em 2014, talvez seja a melhor representação da decadência do partido. Em 2018, por pressões do próprio CNA, Zuma renunciou ao mandato e será investigado criminalmente por suspeita de corrupção. As charges de Zapiro materializaram as frequentes críticas políticas envolvendo o então presidente em casos de desvio de dinheiro e também em escândalos pessoais que marcaram a vida pública do líder zulu.

O ex-presidente da África do Sul se tornou um personagem recorrente na produção chárgica, seja pelas frequentes acusações de corrupção ou pela vida pessoal conturbada. $\mathrm{O}$ mandato de Zuma, de acordo com a representação gráfica de Zapiro, será mais lembrado pela "excentricidade" e pelas polêmicas do que por uma efetiva tentativa de enfrentar os problemas históricos do país, como a desigualdade social, a violência, o racismo, os crimes sexuais e a epidemia de AIDS.

\section{REFERÊNCIAS BIBLIOGRÁFICAS}

CARLIN, John. Conquistando o inimigo: Nelson Mandela e o jogo que uniu a África do Sul. Rio de Janeiro: Sextante, 2009.

DRIGO, Maria Ogécia; SOUZA, Luciana Coutinho Plagliarini de. A charge política jornalística como processo sígnico. Verso e reverso: revista da comunicação, São Leopoldo, v. 20, n. 43, 2006.

FULLER, Alexandra. Os filhos de Mandela. Revista National Geographic Brasil, n.123, p.5281, jun/2010.

JONGE, Klaas de. África do Sul: apartheid e resistência. São Paulo: Cortez; EBOH, 1991.

LUZ, Natália da. "Zuma quis me processar", diz cartunista crítico do próximo presidente sulafricano. Gl.globo.com, 25 abr. 2009. Disponível em: <http://g1.globo.com/Noticias/Mundo/0,,mul1098104-5602,00zuma+quis+me+processar+diz+cartunista+critico+do+proximo+presidente+sulafri.html $>$. Acesso: 15 mai. 2018.

MARINOVICH, Greg; SILVA, João. O clube do bangue-bangue: instantâneos de uma guerra oculta. São Paulo: Companhia das Letras, 2003.

MIANI, Rozinaldo Antonio. As transformações no mundo do trabalho na década de 1990: o olhar atento da charge na imprensa do Sindicato dos Metalúrgicos do ABC paulista. Assis: Unesp, 2005. Tese (Doutorado em História). Faculdade de Ciências e Letras de Assis, Universidade Estadual Paulista, Assis, 2005. 
Charge: uma prática discursiva e ideológica. Revista Nona Arte, São Paulo, v. 1, n. 1, p. $37-48,1^{\circ}$ semestre/2012.

ROMUALDO, Edson Carlos. Charge jornalística: intertextualidade e polifonia: um estudo de charges da Folha de S. Paulo. Maringá: Eduem, 2000.

SANTOS, Renata de Paula dos. Iconografia e política na África do Sul: a representação de Nelson Mandela, Thabo Mbeki e Jacob Zuma nas charges de Zapiro. Londrina: UEL, 2014. Dissertação (Mestrado em Comunicação). Universidade Estadual de Londrina, Londrina, 2014.

VEJA A TRAJETÓRIA DE JACOB ZUMA, DA LUTA ANTI-APARTHEID AOS ESCÂNDALOS DE CORRUPÇÃO. Gl.globo.com, 14 fev. 2018. Disponível em: <https://g1.globo.com/mundo/ noticia/veja-a-trajetoria-de-jacob-zuma-da-luta-anti-apartheidaos-escandalos-de-corrupcao.ghtml>. Acesso em: 15 mai. 2018.

ZAPIRO. Entrevista [respondida por Skype]. Entrevistadora: Renata de Paula dos Santos. Londrina, 2018.

Recebido em: 30/05/2018 Aprovado em: 15/07/2018 